\title{
Evaluation of the middle cerebral artery occlusion techniques in the rat by in-vitro 3-dimensional micro- and nano computed tomography
}

\author{
Alexander C Langheinrich* ${ }^{*} 1$, Mesut Yeniguen ${ }^{+2}$, Anne Ostendorf ${ }^{+1}$, Simone Marhoffer ${ }^{2}$, Marian Kampschulte', \\ Georg Bachmann ${ }^{3}$, Erwin Stolz² and Tibo Gerriets²
}

\begin{abstract}
Background: Animal models of focal cerebral ischemia are widely used in stroke research. The purpose of our study was to evaluate and compare the cerebral macro- and microvascular architecture of rats in two different models of permanent middle cerebral artery occlusion using an innovative quantitative micro- and nano-CT imaging technique.

Methods: $4 \mathrm{~h}$ of middle cerebral artery occlusion was performed in rats using the macrosphere method or the suture technique. After contrast perfusion, brains were isolated and scanned en-bloc using micro-CT $(8 \mu \mathrm{m})^{3}$ or nano-CT at $500 \mathrm{~nm}^{3}$ voxel size to generate 3D images of the cerebral vasculature. The arterial vascular volume fraction and gray scale attenuation was determined and the significance of differences in measurements was tested with analysis of variance $[A N O V A]$.

Results: Micro-CT provided quantitative information on vascular morphology. Micro- and nano-CT proved to visualize and differentiate vascular occlusion territories performed in both models of cerebral ischemia. The suture technique leads to a remarkable decrease in the intravascular volume fraction of the middle cerebral artery perfusion territory. Blocking the medial cerebral artery with macrospheres, the vascular volume fraction of the involved hemisphere decreased significantly $(p<0.001)$, independently of the number of macrospheres, and was comparable to the suture method. We established gray scale measurements by which focal cerebral ischemia could be radiographically categorized $(p<0.001)$. Nano-CT imaging demonstrates collateral perfusion related to different occluded vessel territories after macrosphere perfusion.
\end{abstract}

Conclusion: Micro- and Nano-CT imaging is feasible for analysis and differentiation of different models of focal cerebral ischemia in rats.

\section{Background}

Over the last decade, the rat has become the predominant species for models of focal cerebral ischemia. Up to now, different techniques simulating human cerebral ischemia have been established in rats. Among the endovascular techniques for middle cerebral artery occlusion (MCAO), the suture occlusion technique in rats is the most frequently used method [1-3]. In this model, a monofilament is implemented into the internal carotid artery (ICA) until it blocks blood flow to the middle cere-

\footnotetext{
* Correspondence: alexander.langheinrich@radiol.med.uni-giessen.de

1 Department of Radiology, Justus-Liebig University Giessen, Giessen, Germany + Contributed equally

Full list of author information is available at the end of the article
}

bral artery (MCA). This technique provides reproducible MCA territory infarctions and allows reperfusion by releasing the suture. Permanent MCAO with the suture technique, however, has one disadvantage: insertion of the suture occludes the entire course of the ICA, including the hypothalamic artery. This approach leads to hypothalamic infarction that cause severe hyperthermia with effects on infarct growth, confounding treatment effects $[4,5]$.

The recently introduced macrosphere model has been developed to overcome these side effects by the intraarterial embolization of $\mathrm{TiO}_{2}$ spheres which selectively block blood flow to the MCA main stem without obstructing the hypothalamic artery $[4,6]$. This model 
therefore avoids hypothalamic infarction and pathological hyperthermia in permanent MCA occlusion.

Reliable visualization and detection of cerebral ischemia and particularly the underlying vascular pathology remain a major challenge in vascular research. However, detailed anatomical data about the vascular status, are generally sparse because (i) of the difficulty in their quantification, (ii) of difficulty to demonstrate their interconnectivity to other vessels (collaterals), (iii) of their very fine anatomy in animal models of focal cerebral ischemia.

In the last decade, micro-computed tomography (micro-CT) made it possible to overcome many of these difficulties and permits analysis of the complete 3D branching architecture of small vessels in microscopic detail. Previously, we reported micro-CT's technical feasibility to visualize the intacerebral arteries [7] in apo $\mathrm{E}^{-/}$ $\mathrm{LDL}^{-/}$- double knockout mice. Hence, the purpose of our study was to evaluate micro- and nano-CT's technical feasibility to detect and differentiate structural and functional vascular alterations in two different models of permanent arterial cerebral ischemia in rats.

\section{Methods}

\section{Animal Preparation}

All procedures were performed in accordance with our institutional guidelines and the German animal protection legislation. Male Sprague-Dawley rats (277 to $338 \mathrm{~g}$ bodyweight; Harlan Winkelmann, Borchen, Germany) were anesthetized with $5 \%$ isoflurane delivered in air for 2 minutes. Anesthesia was maintained with $2 \%$ to $3 \%$ isoflurane delivered in air at $0.5 \mathrm{~L} / \mathrm{min}$ during surgery. Body temperature was continuously monitored with a rectal probe and maintained at $36.5^{\circ} \mathrm{C}$ to $37.0^{\circ} \mathrm{C}$. The right external carotid artery (ECA) was ligated and transsected to create an ECA stump with a length of $\sim 5 \mathrm{~mm}$. The pterygopalatine branch of the ICA was also occluded.

\section{Suture Model}

A 4-0 silicone-coated nylon suture was introduced through the ECA stump in animals $(\mathrm{n}=10)$ as described previously [4]. The occluder was advanced into the ICA 16 to $18 \mathrm{~mm}$ beyond the carotid bifurcation until mild resistance indicated that the tip was lodged in the anterior cerebral artery and thus blocked blood flow to the MCA.

\section{Macrosphere Model}

PE-50 tubing, filled with saline and $4 \mathrm{TiO} 2$ macrospheres (diameter, 0.315 to $0.355 \mathrm{~mm}$; BRACE GmbH, Alzenau, Germany), was inserted into the ECA stump $(n=8)$. The tip of the tubing was placed in the carotid bifurcation without affecting the blood flow to the ICA. Then the macrospheres were advanced separately into the ICA by a slow injection of $0.05 \mathrm{~mL}$ saline each, until they were moved passively into the cerebral circulation by the physiological blood flow [6].

\section{Control Animals}

Four additional rats were not subjected to MCA occlusion and served as controls.

\section{Post mortem preparation}

After $4 \mathrm{~h}$, the animals were anesthetized with $5 \%$ isoflurane delivered in air for 2 minutes. Anesthesia was maintained with $2 \%$ to $3 \%$ isoflurane delivered in air at $0.5 \mathrm{~L} /$ min during surgery.

After thoracotomy, PE-50 tubing was inserted into the left ventricle, followed by incision of the right atrium. Then the animal's circulation was flushed with heparinized saline.

The ascending and descending aorta, the subclavian arteries, the external carotid arteries and the pterygopalatine arteries were ligated to avoid unnecessary contrast filling. Then $5 \mathrm{ml}$ Microfil (Flow Tech, Inc., Carver, Massachusetts, USA) was prepared according to the manufacturer's instructions and injected through the aortic arch to fill the arterial and venous cerebral circulation via the internal carotid and the vertebral arteries. Excessive dilatation of the aorta during the injection process was avoided in order to ensure physiological perfusion pressures. After 45 minutes, Microfil formed an elastomeric gel at room temperature. Then the brains including the intact dura mater were removed from the skull and immersed in $4.5 \%$ formalin. Contrast perfusion was performed after 4 hours. Localisation of the suture and the macrospheres within the basal cerebral arteries as well as the presence of subarachnoidal blood was assessed by visual inspection and carefully documented.

According to the previously published criteria, sufficient occlusion of the middle cerebral artery was assumed, if the origin of the MCA-mainstem or all arteries providing blood to the MCA mainstem (i.e. anterior cerebral artery and internal carotid artery) were blocked by macrospheres. Subarachnoid hemorrhage led to exclusion from the study [6].

\section{Micro-Computed Tomography}

All samples were scanned in a micro-computed tomograph (micro-CT) manufactured and developed by SkyScan (SkyScan1072_80 kV; Belgium). The X-ray system is based on a microfocus tube $(20-80 \mathrm{kVp}, 0-100 \mu \mathrm{A})$ reaching a minimum spot size of $8 \mu \mathrm{m}$ at $8 \mathrm{~W}$ generating projection images irradiating X-rays in cone-beam geometry. This system has been described in detail before $[8,9]$. The resulting $3 \mathrm{D}$ images were displayed using image analysis software (Analyze 8.0; Biomedical Imaging Resource, Mayo Clinic, Rochester, MN). For this study, our micro$\mathrm{CT}$ scanner was configured so that the side dimension of 
the cubic voxels was $12 \mu \mathrm{m}$. Gray scale attenuations of micro-CT images were measured in the right and left hemisphere in controls and animals after middle artery occlusion ( $\mathrm{n}=80 /$ brain) using the ANALYZE $^{\odot}$ software package. Therefore, non-contrast perfused animals were used in the Suture Model and in the control group (each $n$ $=3$ ). For determination of relative attenuation values, rectangular regions of interest (ROI; side length, $0.5 \mathrm{~mm}$ at 8 bit) were established manually in areas by non-visible assessment of gray-scale differences.

\section{Nano-Computed Tomography}

For more detailed analysis of the brain microvessels, samples were cut with a side length of $4 \mathrm{~mm}$ and rescanned using a nano-computed tomograph (Nano-CT_2011), manufactured and developed by SkyScan (Kontich, Belgium). The microfocus $\mathrm{X}$-ray source is a pumped type source (open type $\mathrm{x}$-ray source) with a $\mathrm{LaB}_{6}$ cathode. The electron beam is focused by two electromagnetic lenses onto the surface of an $\mathrm{x}$-ray target. The $\mathrm{x}$-ray target $(\mathrm{Au})$ contains a thin tungsten film plated on the surface of the beryllium window producing $\mathrm{x}$-ray emission reaching a minimum spot size of $<400 \mathrm{~nm}$. At this small spot size, small-angle scattering enhances object details down to $150 \mathrm{~nm}$ isotropic voxels size. The X-ray detector consists of a 12-bit digital, water-cooled CCD high-resolution $(1280 \times 1024$ pixel $)$ camera with fibre optic 3.7:1 coupling to an X-ray scintillator and digital frame-grabber. In our experimental setting, samples were positioned on a computer controlled rotation stage and scanned $180^{\circ}$ around the vertical axis in rotation steps of 0.25 degrees at 40 $\mathrm{kVp}$. Acquisition time for each view was 2.4 seconds. Relative position of the object to the source determines geometric magnification and thus the pixel size defined by the cone-beam geometry of the system. Maximum possible magnification is also limited by the specimen size, which has to be within the cone-beam in its horizontal diameter. Raw data were reconstructed with a modified Feldkamp cone-beam reconstruction modus resulting in two dimensional 8-bit gray-scale images consisting of cubic voxels.

\section{Statistical Analysis}

Statistical analysis was performed using JMP 6.0 (SAS Institute, Cary, NC, USA). All data in the text and figures are presented as mean \pm SEM. Vascular volume fraction and gray scale attenuation differences were analyzed using unpaired $t$ test and one-way ANOVA. A value of $p$ $<0.05$ was considered significant in all analyses.

\section{Results}

\section{General Consideration}

Micro-CT and Nano-CT imaging did not provoke any radiographic artefacts, interfering with image analysis.
Using micro-CT imaging, a continuous visualization and quantification of the intracerebral vasculature can be performed. For more detailed information on cerebral microvessels, high-resolution nano-CT imaging can also be used to analyse distinct regions of interest more accurately.

\section{Suture Model}

Figure 1 shows micro-CT findings of a control animal (left column) and of a rat subjected to suture-MCA occlusion (right column). Subarachnoid hemorrhage was found in one of 10 animals as a result of perforation of the intracranial portion of the anterior cerebral artery. This animal was excluded from further evaluation.

Permanent occlusion resulted in a significantly lower vascular volume fraction as compared to the nonoccluded hemisphere $\left(4.02 \pm 1.67 \mathrm{~mm}^{3}\right.$ vs. $11.5 \pm 1.05$ $\mathrm{mm}^{3} ; \mathrm{p}<0.001$; Table 1). Nano-CT imaging indicates a faint contrast filling of the vasculature distal to the occlusion derived by crossflow-filling from the contralateral hemisphere. Moreover, a sparse portion of dye was visible between the suture and the vessel wall, indicating a noncomplete occlusion of the internal carotid artery by the suture (Figure 2).

Gray scale densities were measured and matched to the middle cerebral artery perfusion territories. Animals showed significantly lower gray scale attenuation values as a result of progressive edema.

\section{Macrosphere Model}

Figures 3 demonstrate the typical distribution of macrospheres within the basal cerebral arteries. All administered spheres were detected with micro- and nano-CT imaging.

In 2 animals the macrospheres were lodged exclusively in the anterior and/or posterior cerebral artery without blocking blood flow to the MCA. These animals therefore were excluded from the study since they did not fulfil the predefined criteria for MCA occlusion. As expected, these rats did not show significant differences in the total vascular volume fraction, as compared to controls $(\mathrm{p}<$ 0.2 ). In contrast, animals with correct macrosphere localisation demonstrate a significant decrease $(\mathrm{p}<0.001)$ in the vascular volume fraction $\left(5.5 \pm 1.3 \mathrm{~mm}^{3}\right)$ compared to controls/non-occluded hemisphere (11.6 $\left.\pm 1.2 \mathrm{~mm}^{3}\right)$, indicating sufficient MCA occlusion (Figure 4 and Table 1).

Since the diameter of the macrospheres $(334 \pm 10 \mu \mathrm{m})$ is significantly higher than the occluded vessel (175 to $205 \mu \mathrm{m})$, a complete occlusion can be assumed. However, micro and nano-CT indicates contrast filling of the vasculature distal to the occlusion site (Figure 1). High-resolution nano-CT imaging indicates that distal filling of the middle cerebral artery results from collaterals in the 


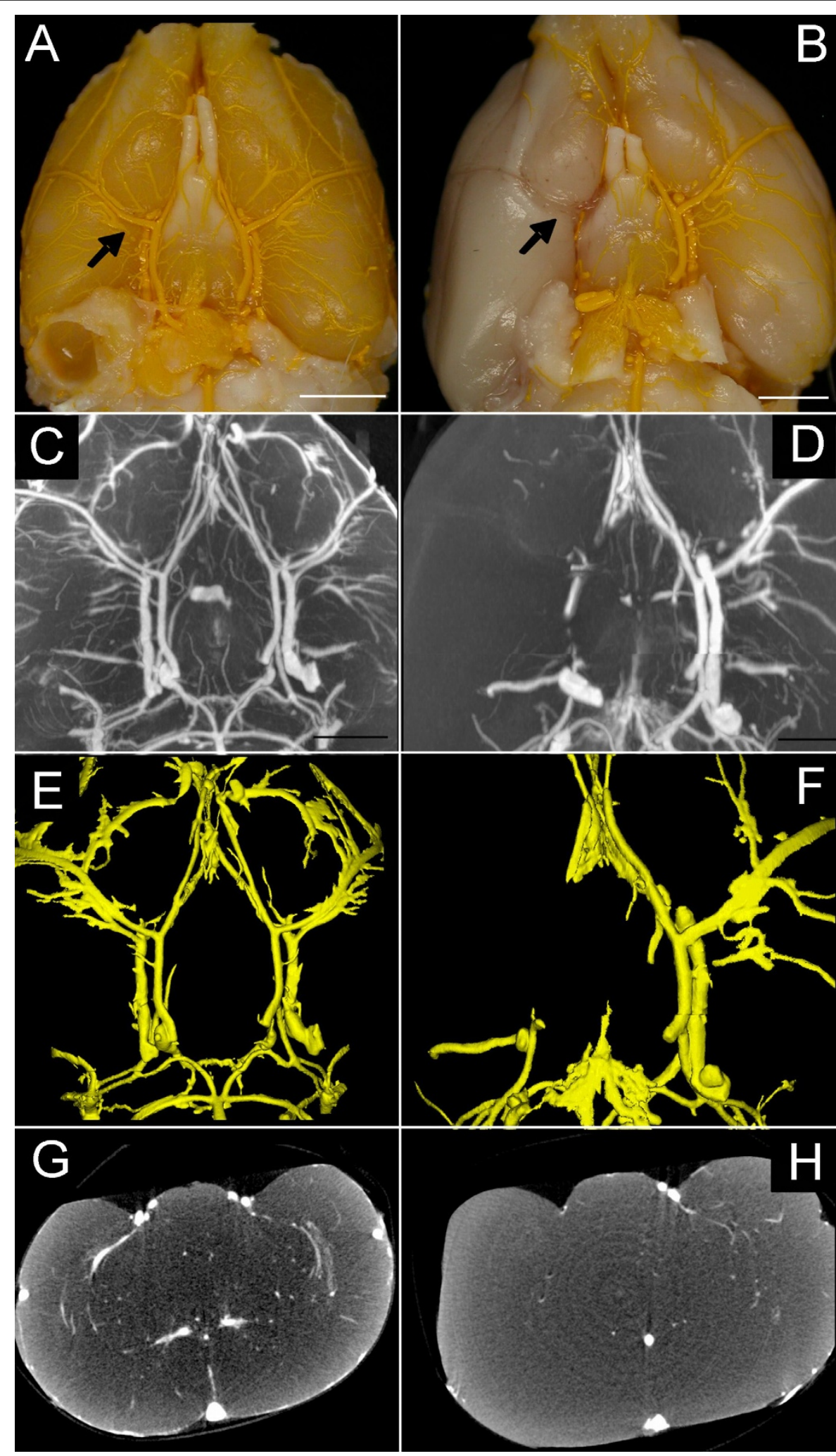

Figure 1 Macroscopic photograph of the rat brain from controls $(\mathbf{A})$ and the suture model (B, bar $=\mathbf{4} \mathbf{m m})$. The suture has been removed and after contrast perfusion, the occluded right part of the circle of willis and the branching middle cerebral artery are demonstrated. Maximum intensity projection $(C, D)$, surface-rendering $(E, F)$ and coronar single-slice micro- $C T$ demonstrate the occluded middle cerebral artery $(D, F, H) c o m p a r e d ~ t o$ controls (C, E, G). 
Table 1: Macrospheres versus Suture Technique.

\begin{tabular}{|c|c|c|c|c|c|c|c|}
\hline & & $\begin{array}{c}\text { Number of } \\
\text { Macrospheres }\end{array}$ & $\begin{array}{c}\text { Vessel } \\
\text { Diameter }(\mu \mathrm{m})\end{array}$ & $\begin{array}{l}\text { Macrosphere } \\
\text { Diameter }(\mu \mathrm{m})\end{array}$ & $\begin{array}{c}\text { Occluded } \\
\text { Vessel } \\
\text { Territories }\end{array}$ & Collaterals via & $\begin{array}{l}\text { Vascular } \\
\text { Volume } \\
\text { (mm3) }\end{array}$ \\
\hline \multirow[t]{4}{*}{ Macrospheres } & $\begin{array}{l}\text { Anterior } \\
\text { Cerebral } \\
\text { Artery }\end{array}$ & 7 & $186 \pm 6^{*}$ & $334 \pm 11$ & No & $\begin{array}{l}\text { Contralateral } \\
\text { Hemisphere }\end{array}$ & $10.9 \pm 0.9$ \\
\hline & $\begin{array}{l}\text { Middle } \\
\text { Cerebral } \\
\text { Artery }\end{array}$ & 7 & $203 \pm 13$ & $335 \pm 7$ & Partial & $\begin{array}{l}\text { Thalamo- } \\
\text { striatal Arteries }\end{array}$ & $5.5 \pm 1.3^{*}$ \\
\hline & $\begin{array}{l}\text { Posterior } \\
\text { Cerebral } \\
\text { Artery }\end{array}$ & 5 & $175 \pm 11^{*}$ & $333 \pm 4$ & No & $\begin{array}{l}\text { Contralateral } \\
\text { Hemisphere }\end{array}$ & $11.4 \pm 0.9$ \\
\hline & Circle of Willis & 16 & $205 \pm 16$ & $333 \pm 8$ & Partial & Unknown & $8.2 \pm 0.8$ \\
\hline \multirow[t]{2}{*}{ Suture } & $\begin{array}{l}\text { Occluded } \\
\text { Hemisphere }\end{array}$ & & & & Partial & Unknown & $4.02 \pm 1.6^{*}$ \\
\hline & \multicolumn{4}{|c|}{ Non-Occluded Hemisphere } & No & & $11.5 \pm 1.1$ \\
\hline
\end{tabular}

The vessel diameter shows significant differences between the anterior and posterior versus the middle cerebral artery and the circle of Willis ${ }^{*}$ $p<0.002)$. The macrosphere diameter is not related to the occluded vessel diameter $(p<0.2)$ but the diameter of the macrospheres shows significantly higher values than the occluded vessel $(p<0.001)$. Macrospheres in the middle cerebral artery showing the same vascular volume fraction as the suture technique.

vicinity of the occlusion site (Figure $1 \mathrm{E}+\mathrm{F}$, black curved arrows). No contrast agent was detectable between the macrospheres and the vessel wall (Figure $1 \mathrm{E}+\mathrm{F}$ ). As a concomitant effect, gray scale value attenuations in the same vascular perfusion territories also significantly decreased (Figure 5) indicating progressive edema due to focal ischemia. No case of subarachnoid hemorrhage was found in the macrosphere model.

\section{Discussion}

For several decades rodent cerebral ischemia models represent a corner stone in stroke research and provided important insights into the underlying pathophysiology of ischemic stroke. Particularly the suture technique has been used frequently, because it is highly reliable and it allows simulating both fundamental conditions of cerebral ischemia: permanent vessel occlusion and ischemia followed by reperfusion. Both conditions are relevant to human stroke and should be taken into account i.e. for the preclinical testing of neuroprotective drugs [10]. Since the pathophysiology of "permanent" and "transient" focal cerebral ischemia is essentially different, animal models should reliably provide these conditions. Permanent MCA occlusion with use of the suture model, how-

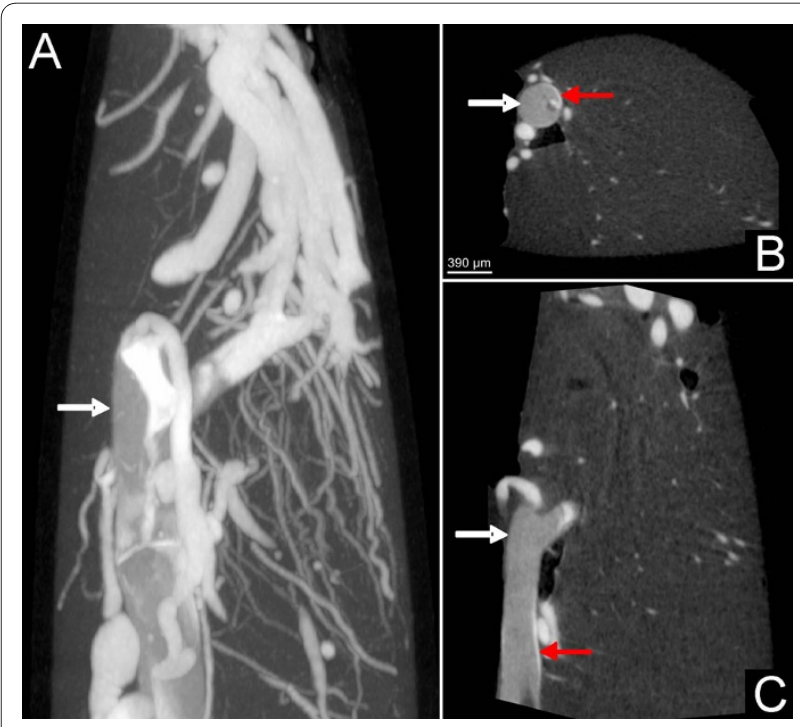

Figure 2 Contrast agent at the top of the suture (white arrow) indicating partial perfusion in the anterior cerebral artery as demonstrated with nano-CT imaging. Note the sparse contrast perfusion between the suture and the vascular wall (red arrow) indicating the non-complete occlusion of the vessel. 


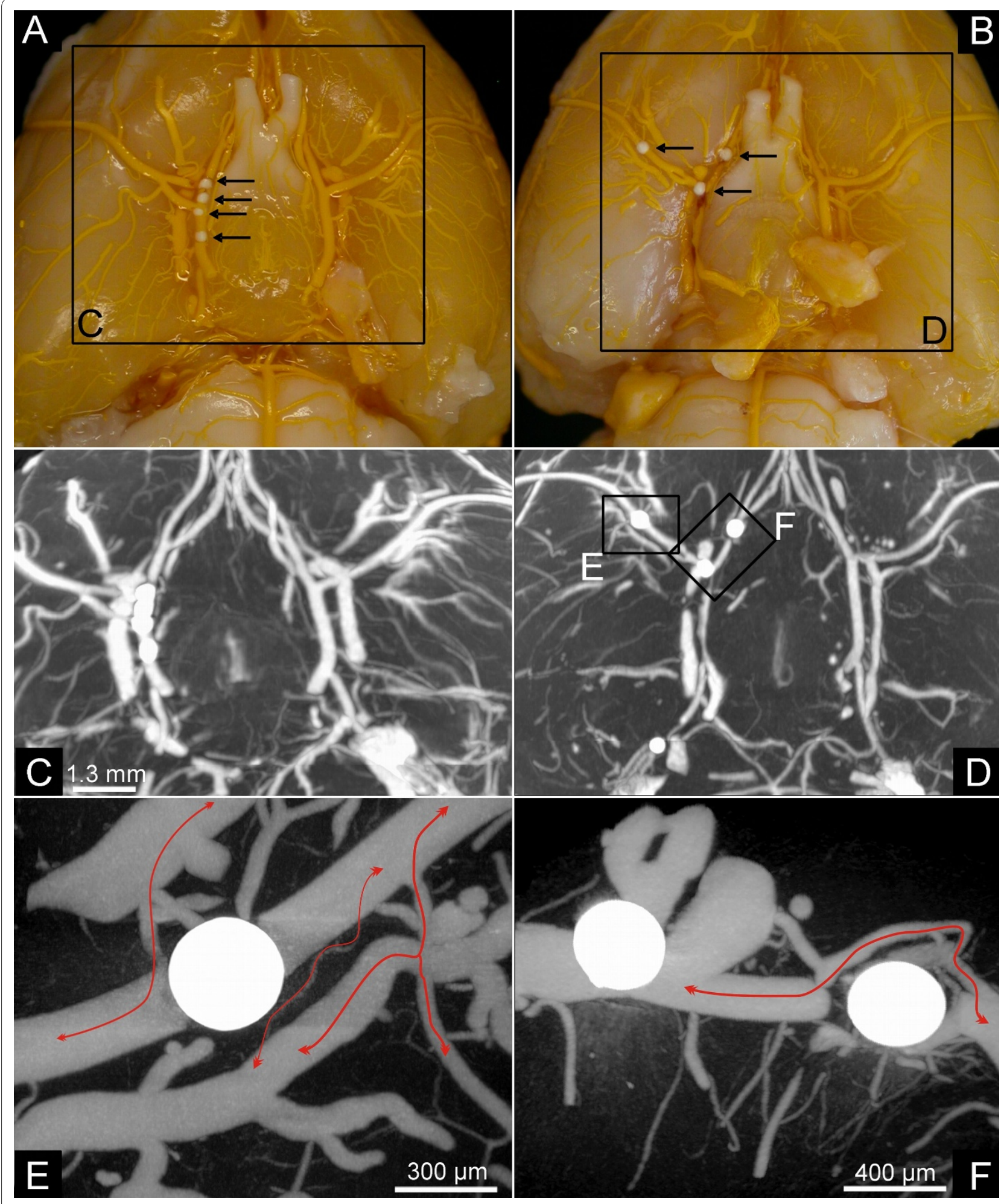

Figure 3 Macrosphere Model. Macroscopic image (A, B) of macrospheres present in the circle of Willis (A) and in the circle of Willis, the anterior cerebral artery and the middle cerebral artery (B). Micro-CT maximum intensity projection (C, D) also demonstrate the macrosphere perfusion territories. Nano-CT imaging (E, F) demonstrate collateral perfusion with contrast-enhanced afferent and efferent vessel perfusion. 


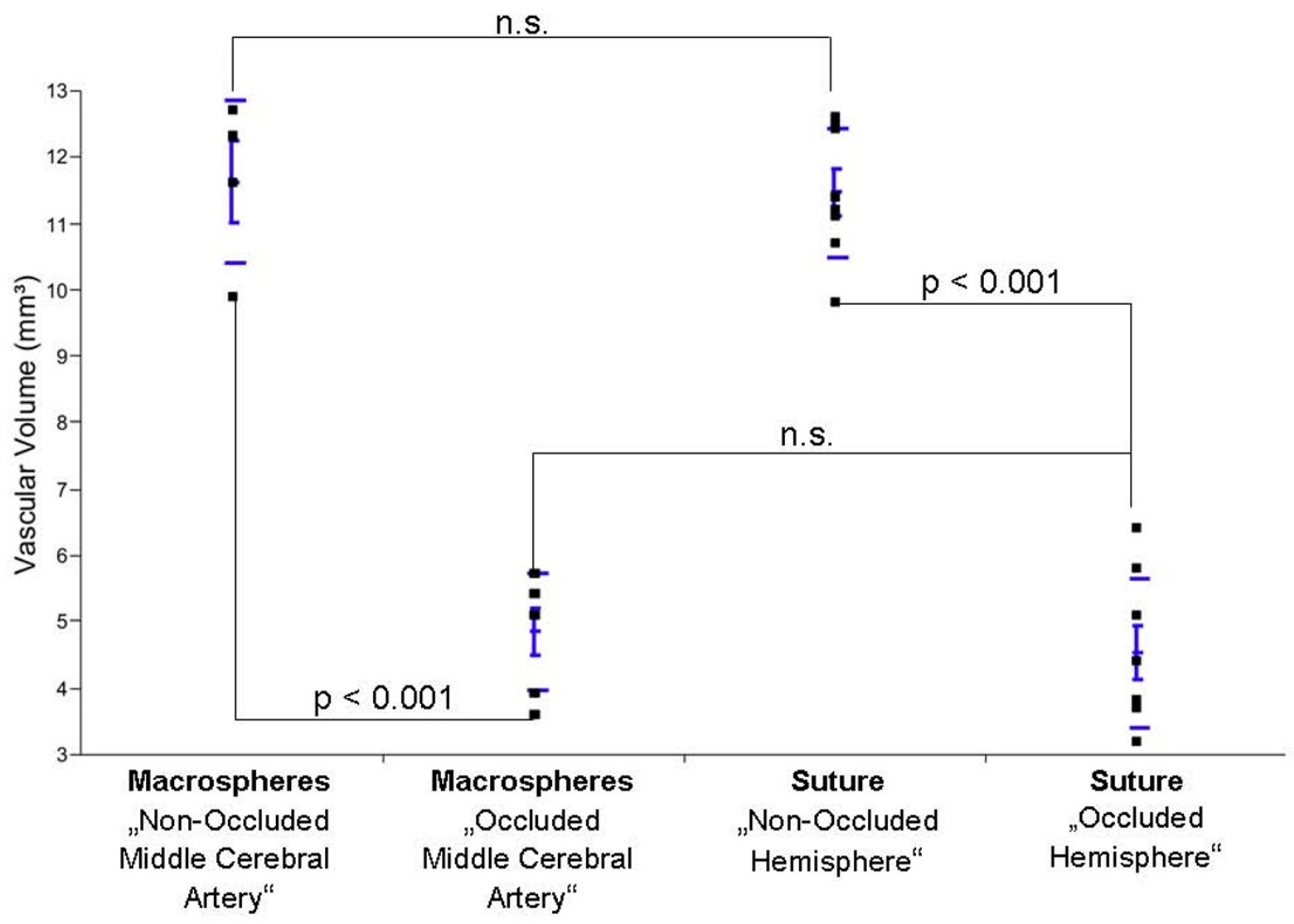

Figure 4 Vascular volume fraction (VVF) in Controls, the Macrosphere- and the Suture Model. Significant differences were found between controls and the macrosphere blocked media territory and the suture technique $(p<0.001)$. Macrospheres in the middle cerebral artery obtained the same results as the suture technique $(p<0.2)$.

ever, has been come under criticism for frequent inadvertent premature reperfusion, as documented by laser Doppler measurements - a side-effect that potentially undermines the strict differentiation between permanent and transient ischemia [3]. The macrospheretechnique in contrast, due to the very tight occlusion of the basal cerebral arteries, has the potential to overcome this side-effect by avoiding bypass blood flow between the vessel wall and the occluder.

The present paper evaluated and compared the vascular anatomy of the permanent suture and the macrosphere MCA occlusion method by using a novel high resolution imaging technique.

The present data indicate that both models of permanent vessel occlusion do not completely block blood flow to the MCA territory. This finding is in accordance with many previous observations using laser Doppler monitoring during the occlusion process with the suture tech- nique, were blood flow in the MCA territory does not drop to zero but is typically reduced by 70 to $90 \%$ [3].

With the use of micro- and nano-CT, we now could visualize for the first time the morphological basis of the remaining perfusion in the two permanent MCA-occlusion models.

1. Distant collateral blood flow from the contralateral hemisphere (cross-flow) was present in both occlusion models, most likely via connections between the ipsilateral and contralateral anterior cerebral artery.

2. Local collateral blood flow in the vicinity of the occluder was an unexpected finding in the macrospheremodel (Figure $1 \mathrm{E}+\mathrm{F}$ ) as well as in the suture technique (Figure 3). Particularly in the macrosphere occlusion method small collateral vessels shifted blood over a short distance from proximal to distal segment of the occluded MCA. This phenomenon was detectable to a much lesser extent in the suture technique, since the suture blocks the 


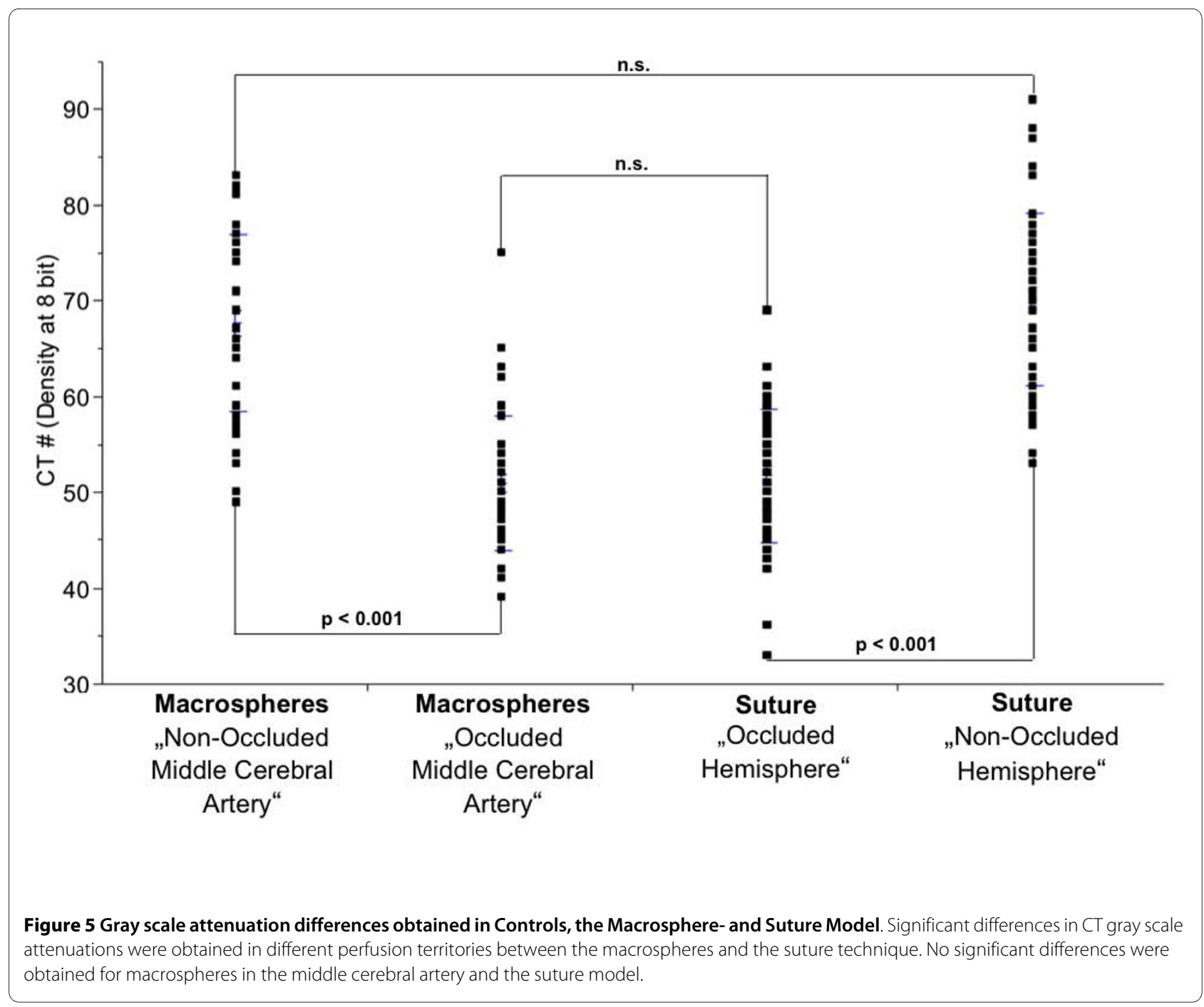

internal carotid artery over its entire distance, which impedes short distance collateral flow.

3. Inadvertent bypass-perfusion between the occluder and the occluded vessel could be detected in the suture model (Figure 3). This finding is most likely related to a discrepancy between the suture diameter and the vessel caliber. Schmidt-Elsaesser and coworkers [3] found a higher proportion of inappropriate MCA occlusion when smaller sutures are used and Laing et al. [11] stated that silicone coated (and therefore thicker) filaments provide denser ischemia than uncoated sutures, would support this hypothesis. The use of thicker sutures than coated 40 filaments, however, seems not to be feasible, since they are difficult to insert through the base of the skull. Inadvertent bypass-perfusion was not detected in the macrosphere model.

In normal Wistar rats, extensive anastomosis among the terminal branches of the three large cerebral arteries have been described and is highest between the anterior and middle cerebral arteries, and also between between the middle and posterior cerebral arteries [12-14]. Microand nano-CT imaging demonstrates that collateral supply to the cortical vascular beds protects in part against complete vascular occlusion and is strongly related to the blocked macrosphere perfusion territory. Those findings are in line with the published literature [15-17], indicating pre-existing anastomosis and collaterals after middle cerebral artery occlusion in rats.

Imaging methods are indispensable for studying the vessel architecture in animal models of vascular disorders. Despite the power and utility of these research methods, there is still a large difference in spatial resolution between microscopy-based imaging methods and clinical methods. High-resolution magnetic resonance angiography (MRA) has been introduced as a means to investigate the arterial cerebrovascular hemodynamics noninvasively in rats $[1,18]$ and mice [19]. Up to now, MRI imaging is the most frequently used method to 
investigate cerebral perfusion in experimental $[20,21]$ and clinical conditions [22,23]. Major limitations using MRI imaging is the spatial resolution needed to visualize and quantify changes in the microvasculature. Clinical and experimental studies addressed these aspects using 3, 4.7, 7 and 11.7 Tesla systems [1,24-27].

Micro-CT has made it possible to largely overcome these difficulties and permit analysis of the complete 3D branching architecture of small vessels in microscopic detail $[28,29]$. Moreover, Micro-CT imaging makes it possible to quantify the number and spacing of blood vessels, [30] and vascular permeability [31]. Micro-CT in the present study emerged as a sensitive technique to detect vessel alterations in different models of focal brain ischemia. The 3D micro-CT images have several advantages over 2D histology, as one can unambiguously identify a vessel along its entire length from the vessel's origin to the terminal region.

\section{Conclusion}

This study demonstrates a methodological approach to preserve and examine the rat cerebral vasculature under physiological and pathological conditions. To our knowledge, this is the first study using micro-CT and nano-CT technique for imaging the intracerebral vasculature nondestructively in different models of focal brain ischemia.

The present data indicate that rodent models of "permanent" MCA occlusion provide a certain amount of remaining perfusion via different collateral pathways and (in case of the suture technique) also by inadvertent bypass-perfusion along the filament. These findings emphasize the thesis, that unadulterated permanent ischemic conditions can not be simulated with the present rodent stroke models since they all contain some elements of reperfusion.

\section{Competing interests}

The authors declare that they have no competing interests.

\section{Authors' contributions}

$A C L, M K$, and $A O$ carried out the micro-CT studies and drafted the manuscript. Animal preparation and perfusion was performed by MY and SM. GB, ES and TG participated in its design and coordination and helped to draft the manuscript. All authors read and approved the final manuscript.

\section{Acknowledgements}

We would like to thank Gunhild Martels, Justus-Liebig University of Giessen, for technical assistance. The investigation was supported in part by grants from the german research foundation (DFG; 162/291-1 FUGG).

\section{Author Details}

1Department of Radiology, Justus-Liebig University Giessen, Giessen, Germany, 2Department of Neurology, Experimental Neurology Research Group, JustusLiebig University Giessen, Giessen, Germany and 3Department of Radiology, Kerckhoff Clinic, Bad Nauheim, Germany

Received: 22 September 2009 Accepted: 28 May 2010

Published: 28 May 2010
References

1. Gerriets T, Stolz E, Walberer M, Muller C, Rottger C, Kluge A, Kaps M, Fisher M, Bachmann G: Complications and pitfalls in rat stroke models for middle cerebral artery occlusion: a comparison between the suture and the macrosphere model using magnetic resonance angiography. Stroke 2004, 35:2372-2377.

2. Gerriets T, Stolz E, Walberer M, Muller C, Kluge A, Kaps M, Fisher M, Bachmann G: Middle cerebral artery occlusion during MR-imaging: investigation of the hyperacute phase of stroke using a new in-bore occlusion model in rats. Brain Res Brain Res Protoc 2004, 12:137-143.

3. Schmid-Elsaesser R, Zausinger S, Hungerhuber E, Baethmann A, Reulen $\mathrm{HJ}$ : A critical reevaluation of the intraluminal thread model of focal cerebral ischemia: evidence of inadvertent premature reperfusion and subarachnoid hemorrhage in rats by laser-Doppler flowmetry. Stroke 1998, 29:2162-2170.

4. Gerriets T, Stolz E, Walberer M, Kaps M, Bachmann G, Fisher M: Neuroprotective effects of MK-801 in different rat stroke models for permanent middle cerebral artery occlusion: adverse effects of hypothalamic damage and strategies for its avoidance. Stroke 2003, 34:2234-2239.

5. Memezawa H, Zhao Q, Smith ML, Siesjo BK: Hyperthermia nullifies the ameliorating effect of dizocilpine maleate (MK-801) in focal cerebral ischemia. Brain Res 1995, 670:48-52.

6. Gerriets T, Li F, Silva MD, Meng X, Brevard M, Sotak CH, Fisher M: The macrosphere model: evaluation of a new stroke model for permanent middle cerebral artery occlusion in rats. J Neurosci Methods 2003, 122:201-211.

7. Langheinrich AC, Michniewicz A, Bohle RM, Ritman EL: Vasa vasorum neovascularization and lesion distribution among different vascular beds in ApoE-/-/LDL-/- double knockout mice. Atherosclerosis 2007, 191:73-81.

8. Langheinrich AC, Leithauser B, Greschus S, Von Gerlach S, Breithecker A, Matthias FR, Rau WS, Bohle RM: Acute rat lung injury: feasibility of assessment with micro-CT. Radiology 2004, 233:165-171.

9. Langheinrich AC, Bohle RM, Breithecker A, Lommel D, Rau WS: [Microcomputed tomography of the vasculature in parenchymal organs and lung alveoli]. Rofo 2004, 176:1219-1225.

10. Recommendations for standards regarding preclinical neuroprotective and restorative drug development. Stroke 1999, 30:2752-2758.

11. Laing RJ, Jakubowski J, Laing RW: Middle cerebral artery occlusion without craniectomy in rats. Which method works best? Stroke 1993, 24:294-298

12. Coyle P, Jokelainen PT: Dorsal cerebral arterial collaterals of the rat. Anat Rec 1982, 203:397-404.

13. Coyle P: Dorsal cerebral collaterals of stroke-prone spontaneously hypertensive rats (SHRSP) and Wistar Kyoto rats (WKY). Anat Rec 1987, 218:40-44.

14. Coyle P: Cerebral collateral patterns in normal Wistar rats. Acta Physiol Scand Supp/ 1986, 552:5-8.

15. Coyle P: Middle cerebral artery occlusion in the young rat. Stroke 1982, 13:855-859

16. Coyle P: Spatial relations of dorsal anastomoses and lesion border after middle cerebral artery occlusion. Stroke 1987, 18:1133-1140.

17. Coyle P, Heistad DD: Blood flow through cerebral collateral vessels one month after middle cerebral artery occlusion. Stroke 1987, 18:407-411.

18. Reese T, Bochelen D, Sauter A, Beckmann N, Rudin M: Magnetic resonance angiography of the rat cerebrovascular system without the use of contrast agents. NMR Biomed 1999, 12:189-196.

19. Beckmann N: High resolution magnetic resonance angiography noninvasively reveals mouse strain differences in the cerebrovascular anatomy in vivo. Magn Reson Med 2000, 44:252-258.

20. Rother J, Waggie K, van Bruggen N, de Crespigny AJ, Moseley ME: Experimental cerebral venous thrombosis: evaluation using magnetic resonance imaging. J Cereb Blood Flow Metab 1996, 16:1353-1361.

21. McDannold N, Vykhodtseva N, Jolesz FA, Hynynen K: MRI investigation of the threshold for thermally induced blood-brain barrier disruption and brain tissue damage in the rabbit brain. Magn Reson Med 2004, 51:913-923

22. Vernooij MW, Ikram MA, Tanghe HL, Vincent AJ, Hofman A, Krestin GP, Niessen WJ, Breteler MM, van der LA: Incidental findings on brain MRI in the general population. N Engl J Med 2007, 357:1821-1828. 
23. Nilsson P, Sandberg-Wollheim M, Norrving B, Larsson EM: The role of MRI of the brain and spinal cord, and CSF examination for the diagnosis of primary progressive multiple sclerosis. Eur J Neurol 2007, 14:1292-1295.

24. De Vita E, Thomas DL, Roberts S, Parkes HG, Turner R, Kinchesh P, Shmueli $\mathrm{K}$, Yousry TA, Ordidge RJ: High resolution MRI of the brain at 4.7 Tesla using fast spin echo imaging. Br J Radiol 2003, 76:631-637.

25. Bernstein MA, Huston J, Lin C, Gibbs GF, Felmlee JP: High-resolution intracranial and cervical MRA at 3.0T: technical considerations and initial experience. Magn Reson Med 2001, 46:955-962.

26. Pfeuffer J, Adriany G, Shmuel A, Yacoub E, Moortele PF Van De, Hu X, Ugurbil K: Perfusion-based high-resolution functional imaging in the human brain at 7 Tesla. Magn Reson Med 2002, 47:903-911.

27. Glover PM, Bowtell RW, Brown GD, Mansfield P: A microscope slide probe for high resolution imaging at 11.7 Tesla. Magn Reson Med 1994 31:423-428.

28. Gossl M, Malyar NM, Rosol M, Beighley PE, Ritman EL: Impact of coronary vasa vasorum functional structure on coronary vessel wall perfusion distribution. Am J Physiol Heart Circ Physiol 2003, 285:H2019-H2026.

29. Gossl M, Rosol M, Malyar NM, Fitzpatrick LA, Beighley PE, Zamir M, Ritman EL: Functional anatomy and hemodynamic characteristics of vasa vasorum in the walls of porcine coronary arteries. Anat Rec A Discov Mol Cell Evol Biol 2003, 272:526-537.

30. Gossl M, Zamir M, Ritman EL: Vasa vasorum growth in the coronary arteries of newborn pigs. Anat Embryol (Berl) 2004, 208:351-37.

31. Gossl M, Beighley PE, Malyar NM, Ritman EL: Role of vasa vasorum in transendothelial solute transport in the coronary vessel wall: a study with cryostatic micro-CT. Am J Physiol Heart Circ Physiol 2004, 287: $\mathrm{H} 2346-\mathrm{H} 2351$.

\section{Pre-publication history}

The pre-publication history for this paper can be accessed here: http://www.biomedcentral.com/1471-2377/10/36/prepub

doi: 10.1186/1471-2377-10-36

Cite this article as: Langheinrich et al., Evaluation of the middle cerebral artery occlusion techniques in the rat by in-vitro 3-dimensional micro- and nano computed tomography BMC Neurology 2010, 10:36

Submit your next manuscript to BioMed Centra and take full advantage of:

- Convenient online submission

- Thorough peer review

- No space constraints or color figure charges

- Immediate publication on acceptance

- Inclusion in PubMed, CAS, Scopus and Google Scholar

- Research which is freely available for redistribution

Submit your manuscript at www.biomedcentral.com/submit
C Biomed Central 